\title{
JAPANESE FOREIGN EXCHANGE INTERVENTION AND THE YEN/DOLLAR EXCHANGE RATE: A SimultaneOUS EQUATIONS APPROACH USING REALIZED VOLATILITY
}

\author{
ERIC HILLEBRAND \\ GUNTHER SCHNABL \\ YASEMIN ULU
}

CESIFO WORKING PAPER NO. 1766

CATEgory 6: MONETARY POLICY AND INTERNATIONAL FINANCE

JULY 2006

An electronic version of the paper may be downloaded

- from the SSRN website:

www.SSRN.com

- from the RePEc website:

www.RePEc.org

- from the CESifo website:

www.CESifo-group.de 


\title{
JAPANESE FOREIGN EXCHANGE INTERVENTION AND THE YEN/DOLLAR EXCHANGE RATE: A SIMULTANEOUS EQUATIONS APPROACH USING REALIZED VOLATILITY
}

\begin{abstract}
We use realized volatility to study the influence of central bank interventions on the yen/dollar exchange rate. Realized volatility is a technical innovation that allows specifying a system of equations for returns, realized volatility, and interventions without endogeneity bias. We find that during the period 1995 through 1999, interventions of the Japanese monetary authorities did not have the desired effect with respect to the exchange rate level and we measure an increase in volatility associated with interventions. During the period 1999 through 2004, the estimations are consistent with successful interventions, both in depreciating the yen and in reducing exchange rate volatility.

JEL Code: C32, E58, F31, F33, G15.
\end{abstract}

\author{
Eric Hillebrand \\ Department of Economics \\ Louisiana State University \\ Baton Rouge \\ LA 70803 \\ USA \\ erhil@lsu.edu
}

\author{
Gunther Schnabl \\ Department of Economics and Business \\ Administration \\ Leipzig University \\ Marschnerstr. 31 \\ 04109 Leipzig \\ Germany \\ schnabl@wifa.uni-leipzig.de
}

\author{
Yasemin Ulu \\ American University of Beirut \\ Riad El Solh \\ Beirut 11072020 \\ Lebanon \\ yb06@aub.edu.lb
}




\section{Introduction}

Since the Japanese monetary authorities have released data on their foreign exchange intervention activities in 2001, a steadily increasing number of studies have scrutinized the effects of Japanese foreign exchange intervention. One of the main challenges to address is an endogeneity problem: If there is significant correlation between interventions and exchange rate returns or volatility, does this support the hypothesis that interventions cause changes in exchange rate movements or does this support the reverse direction that exchange rate movements trigger interventions? Building upon the paper of Dominguez (1998), the studies of Ito (2003), Frenkel, Pierdzioch and Stadtmann (2005), Watanabe and Harada (2006), and Hillebrand and Schnabl (2006), among others, have used daily yen/dollar time series in a GARCH framework to study the impact of Japanese foreign exchange intervention on the volatility of the yen/dollar exchange rate. Instead of trying to measure the success of interventions in pushing the exchange rate to a desired level, these studies use the smoothing of exchange rate volatility as a success criterion. The coefficients in the GARCH mean equations were rendered uninterpretable by endogeneity bias. Separate estimations of reaction functions for the monetary authorities usually found that interventions correlated with exchange rate returns but not with volatility. Therefore, endogeneity did not seem to be a problem in the conditional volatility equation, at least not if one accounted for linear effects only. These studies found mixed evidence that Japanese foreign exchange interventions have increased or decreased exchange rate volatility, depending on the time period.

As the GARCH time series approaches have not been able to fully resolve the endogeneity issue, a new strand of literature has evolved that has used event studies to analyze the success of Japanese foreign exchange intervention (Neely 2005). Fatum and Hutchison (2003) separate intervention episodes and analyze the subsequent effects on the exchange rate. They find evidence in favor of successful Japanese intervention, as mean exchange rate changes after intervention are statistically smaller than the mean pre-intervention change. 
Kearns and Rigobon (2005) specify a multiple equation model for returns and interventions that uses a change in intervention policies to identify the parameters. Kim (2003) proposes a structural VAR model for returns and interventions and estimates the effects of intervention and monetary policy with monthly data.

The concept of realized volatility introduced by Andersen and Bollerslev (1998) allows us to consider volatility as an observed rather than as a latent variable. Therefore, we can specify a system of equations that contains not only returns and interventions but also realized volatility. Such a system provides a comprehensive framework to study the interplay of the first and the second moment of the return distribution of the yen/dollar rate with interventions without endogeneity bias.

Using a total sample period from 1995 through 2004, we find a change-point in the time series of realized volatility in December 1999. Estimating the system of equations on the resulting sub-periods, we find that during the period 1995-1999, Japanese foreign exchange interventions were not successful, neither in influencing the returns nor in reducing the volatility of the yen/dollar rate. On the contrary, we measure a significantly positive coefficient of interventions in the volatility equation. In the period 1999-2004, the estimations are consistent with successful interventions, both in depreciating the yen and in reducing volatility. The results therefore indicate a change toward a more successful intervention policy.

\section{Realized Volatility}

Returns of financial assets display volatility clustering: large movements in prices tend to be followed by more large movements. In other words, current and past volatility can be used to predict future volatility. This serial correlation motivates almost all extant volatility models. Before the introduction of the concept of realized volatiity, however, volatility was not directly observable, 
and models like GARCH or Stochastic Volatility use squared or absolute returns calculated from daily or lower frequency time series to estimate a latent volatility process.

Andersen and Bollerslev (1998) argue that squared daily returns are a very noisy estimator and introduce realized volatility as a new volatility measure. Realized volatility is the sum of high-frequency intra-day squared returns. The motivation for this statistic is the common practice to model the log price process of an asset as a continuous martingale. For continuous martingales the sum of squared increments converges to the quadratic variation as the partition on which the increments are computed becomes finer. The quadratic variation, in turn, is the variance of increments of the continuous martingale. In an asset price model, the quadratic variation therefore is the integrated volatility. Andersen, Bollerslev, Diebold, and Labys (2001) show this in a general framework.

Let us consider the special case of an Itô process with constant drift, that is, the log asset price $X(t)$ at time $t$ is given by the stochastic differential equation

$$
d X(t)=\mu d t+\sigma(t) d W(t)
$$

where $W(t)$ denotes standard Brownian Motion, $\mu$ is the drift parameter and $\sigma(t)$ is the diffusion parameter as a function of time. The function may be deterministic or stochastic. The quadratic variation $\langle X\rangle(t)$ is given by

$$
\langle X\rangle(t)=\lim _{\|\Pi\| \rightarrow 0} \sum_{j=1}^{n}\left|X\left(\tau_{j}\right)-X\left(\tau_{j-1}\right)\right|^{2},
$$

where $\|\Pi\|$ is the mesh of the partition $\Pi=\left\{\tau_{0}=0, \tau_{1}, \ldots, \tau_{n}=t\right\}$ of the interval $[0, t]$. The increment

$$
r(t):=X(t)-X(t-1)=\mu+\int_{t-1}^{t} \sigma(s) d W(s)
$$

is normally distributed

$$
r(t) \sim \mathcal{N}\left(\mu, \int_{t-1}^{t} \sigma^{2}(s) d s\right) .
$$

If $\sigma(t)$ is a stochastic process (the more appropriate model for financial volatility), then the distribution (2) is conditional on the sigma-algebra generated by 
the path of $\sigma(s), 0 \leq s \leq t-1$. It follows from the Itô isometry that the quadratic variation is given by

$$
\langle X\rangle(t)=\int_{0}^{t} \sigma^{2}(s) d s,
$$

or $\int_{0}^{t} \mathbb{E}_{0} \sigma^{2}(s) d s$ in the case of a stochastic volatility process. This integrated volatility and equation (1) suggest that the volatility in (2) can be measured arbitrarily exactly by calculating

$$
\langle X\rangle(t)-\langle X\rangle(t-1)=\sum_{j=1}^{n}\left|X\left(\tau_{j}\right)-X\left(\tau_{j-1}\right)\right|^{2},
$$

on the partition $\Pi=\left\{\tau_{0}=t-1, \tau_{1}, \ldots, \tau_{n}=t\right\}$ of the interval $[t-1, t]$ and choosing the mesh $\|\Pi\|$ sufficiently small. Therefore, as an estimator of integrated volatility that uses intra-day data, realized volatility is much more precise than estimators using daily data or lower frequencies.

Microstructure effects like the bid-ask bounce and discreteness of prices prevent too fine a grid. Barndorff-Nielsen and Shephard (2002) study the properties of the estimation error of realized volatility. For the purposes of our study, the main advantage of realized volatility is that volatility can be treated as observable rather than latent. This allows us to set up a system of equations for returns and volatility of the yen/dollar exchange rate as well as interventions in the yen/dollar market.

\section{Data}

We use high-frequency intra-day and daily data provided by Olsen Financial Technologies, Bloomberg, the Japanese Ministry of Finance, and the Federal Reserve Board. The sample period is 2-Jan-1995 through 30-Dec-2004. This corresponds to a sample size of 2601 days. The start point of the sample period in 1995 is dictated by our base of high-frequency data.

Following Andersen, Bollerslev, Diebold and Labys (2001), Andersen, Bollerslev, Diebold, and Ebens (2001) as well as Barndorff-Nielsen and Shephard 
(2002), we use 5-minute returns on the yen/dollar exchange rate. The provider Olsen Financial Technologies filters the high frequency data for outliers and the 5-minute prices are obtained by linearly interpolating the average of log-bid and log-ask for two closest ticks. We delete the weekends from Friday 21:05 Greenwich Mean Time (GMT) until Sunday 21:05 GMT. Christmas (Dec 24-26), New Year (Dec 31-Jan 2) and the Fourth of July are also removed from the data set. The daily realized volatilities are constructed by the sum of the square of the 5-minute intra-day returns as in (3).

The daily interventions of the Japanese monetary authorities are reported on the web site of the Japanese Ministry of Finance. The exact intervention time, the number of interventions within a day, the intervention market (Tokyo, London, or New York), and the exchange rate at the time of intervention remain undisclosed. The reported amounts are in billion yen; we convert them into billion dollars based on daily exchange rates. The US foreign exchange intervention data are provided by the Federal Reserve Board.

Other time series used are the daily Nikkei 300 (Bloomberg series NEY), the Federal Funds Rate (Bloomberg: FDFD), and the Japanese uncollateralized overnight interbank interest rate (Bloomberg: JYMU1T). The latter is available only after 11-Apr-1996. Figure 1 shows plots of the three main considered series that we will model in a system of equations: The daily returns on the yen/dollar exchange rate, the realized volatility of the yen/dollar exchange rate, and the time series of pooled Japanese and US interventions.

\section{Structural Breaks in Volatility}

The periods of high and low volatility that can be seen in the first and second panel of Figure 1 can be understood as different parameter regimes interrupted by structural breaks, that is, changes in the data-generating parameters of the volatility model under study. The possibility of structural breaks and its im- 

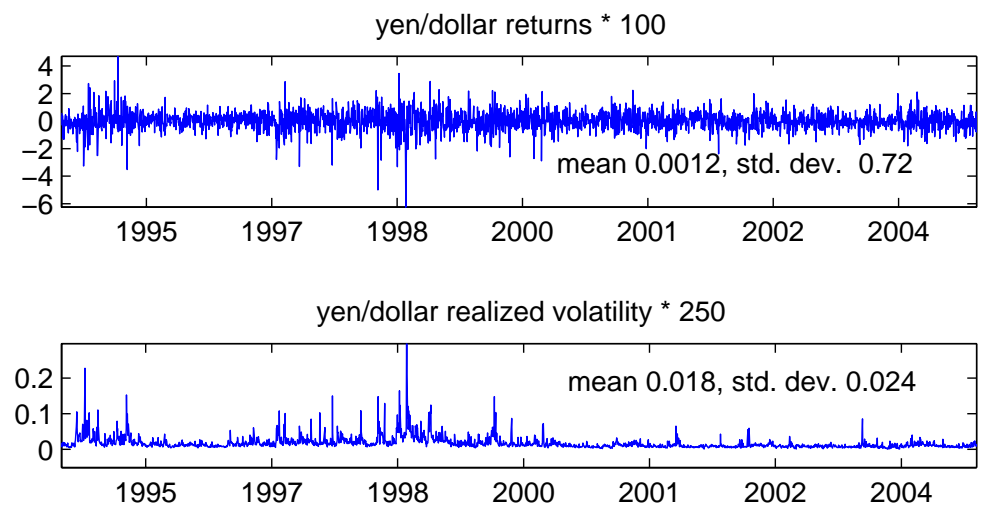

interventions in bn dollars

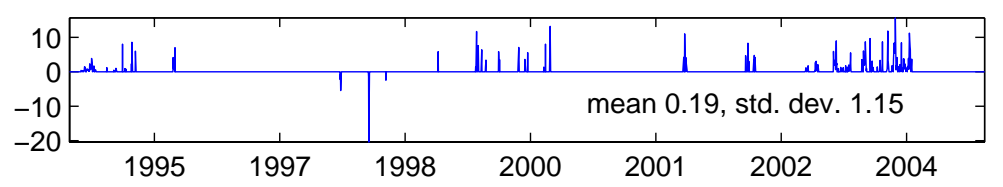

Figure 1: Yen/dollar returns and realized volatility, interventions by Japanese and U.S. authorities during 1995 to 2004.

plications for the estimation of serial correlation and persistence in volatility has been discussed widely (Andreou and Ghysels 2002, Bos, Franses, and Ooms 1999, Diebold and Inoue 2001, Granger and Hyung 1999, Hillebrand 2005, Lamoureux and Lastrapes 1990, LeBaron 2001, Mikosch and Starica 2004). Earlier studies in the intervention literature have indeed found evidence for structural breaks in the yen-dollar exchange rate (Ito 2003, Hillebrand and Schnabl 2006).

We apply the change-point detector statistic proposed in Bai $(1994,1997)$ to the series of realized volatilities displayed in the second panel of Figure 1. The asymptotic theory developed by Bai will hold as long as realized volatility can be described by a linear time series model. We need an estimator of the variance of the realized volatility series in order to compute the statistic. We choose the VARHAC estimator of Den Haan and Levin (1997) for this purpose. 
At the $99 \%$ confidence level, the detector returns one significant change-point at 1-Dec-1999. The corresponding test statistic converges in distribution under the null to a standard Brownian Bridge. The test statistic is 3.10, which implies a 1e-8 probability under the null. Visually inspecting the second panel of Figure 1 , an estimated change-point around the year 2000 is no surprise.

\section{A Simultaneous Equations Model of Exchange Rate Moments and Intervention}

In this section, we estimate the system $y_{t}=\left(r_{t}, \log \sigma_{t}^{2}, I_{t}\right)$, where $r_{t}$ are the daily log returns of the yen/dollar exchange rate, $\sigma_{t}^{2}$ is the daily realized volatility of the yen/dollar exchange rate, and $I_{t}$ are the pooled interventions by the Japanese and U.S. monetary authorities. The U.S. interventions make up only a very small fraction in this sample. ${ }^{1}$ The interventions are recorded at Tokyo time. The high-frequency quotes of the yen/dollar exchange rate are recorded at Greenwich Mean Time, which lags Tokyo time by nine hours. Therefore, interventions $I_{t}$ at (Tokyo-) time $t$ clearly precede the returns $r_{t}$ and the realized volatility $\sigma_{t}^{2}$ (at GMT). Sometimes, the Federal Reserve intervenes on behalf of the Japanese authorities. There are no publicly available data on these transactions. Since the high-frequency quotes cover the entire day until 24:00 GMT corresponding to 19:00 Eastern Standard Time, any immediate effects of these interventions will still be reflected in the returns $r_{t}$ and realized volatility $\sigma_{t}^{2}$.

\footnotetext{
${ }^{1}$ There are two periods where the Federal Reserve intervened during the sample period. The first was between 2-Mar-1995 and 15-Aug-1995. All interventions were coordinated with the Japanese monetary authorities, had the same sign and purpose, and occurred on the same days. During this time, the Japanese authorities intervened on 34 days. The Federal Reserve supported these interventions on 8 days. The Dollar purchases of the Japanese authorities amounted to $\$ 35.4 \mathrm{bn}$ during this period. The purchases of the Federal Reserve amounted to $\$ 3.3 \mathrm{bn}$. The other instance was 17-Jun-1998, when the Federal Reserve supported a Japanese sale of Dollars ( $\$ 1.6 \mathrm{bn})$ by selling $\$ 0.8 \mathrm{bn}$.
} 


\subsection{Specification}

We will consider the following linear system of equations

$$
\begin{aligned}
r_{t} & =\alpha_{0}+\alpha_{1} I_{t}+u_{t}, \\
\log \sigma_{t}^{2} & =\beta_{0}+\beta_{1} \log \sigma_{t-1}^{2}+\beta_{2} \log \sigma_{t-1, w}^{2}+\beta_{3} \log \sigma_{t-1, m}^{2}+\beta_{4} I_{t}+v_{t}, \\
I_{t} & =\gamma_{1} I_{t-1}+\gamma_{2} r_{t}+\gamma_{3} r_{t-1}+\gamma_{4} \sigma_{t}^{2}+\gamma_{5} \sigma_{t-1}^{2}+w_{t}
\end{aligned}
$$

where $r_{t}$ are the daily log returns of the yen/dollar exchange rate, $\sigma_{t}^{2}$ is the daily realized volatility, $\sigma_{t, w}^{2}$ is realized volatility aggregated at the weekly level (5 days), $\sigma_{t, m}^{2}$ is realized volatility aggregated at the monthly level (20 days), and $I_{t}$ are the interventions. The specification of the volatility equation is in the spirit of the HAR-RV model (Corsi 2004).

The parameter vector to be estimated is

$$
\theta=\left(\alpha_{0}, \alpha_{1}, \beta_{0}, \beta_{1}, \beta_{2}, \beta_{3}, \beta_{4}, \gamma_{1}, \gamma_{2}, \gamma_{3}, \gamma_{4}, \gamma_{5}\right)
$$

We cannot make standard distribution assumptions on the error terms because the intervention time series is equal to zero most of the time and has pronounced clusters of large interventions (Figure 1). We therefore estimate the system by GMM, which does not require a specific error distribution to derive inferences.

In order to capture the influence of other asset markets on the exchange rate and interventions, we include the returns on the daily Nikkei 300 index in equation (4) (with coefficient $\alpha_{2}$ ), its squared returns in equation (5) (with coefficient $\beta_{5}$ ), and both returns and squared returns in equation (6) (with coefficients $\left.\gamma_{6}, \gamma_{7}\right)$. This results in a nuisance parameter vector

$$
\tilde{\theta}=\left(\alpha_{2}, \beta_{5}, \gamma_{6}, \gamma_{7}\right)
$$

which we estimate alongside $\theta .^{2}$ Changes in the interest rate are another possible transmission channel of interventions and we will extend the system to include

\footnotetext{
${ }^{2}$ We also included the Dow Jones Industrial Average in addition to the Nikkei and replacing the Nikkei. The results were very similar.
} 
the Japanese overnight rate and the US-Japanese interest rate differential in a second set of estimations. ${ }^{3}$

Before the theory of realized volatility was available, equations (4) and (5) were usually specified in a GARCH framework with interventions as exogenous variables. Equation (6), the reaction function of the monetary authorities, had to be estimated separately. Examples for studies that follow this approach are Dominguez (1998), Bonser-Neal and Tanner (1996), and Hillebrand and Schnabl (2006), among others. In this setup, volatility was latent and the equations (4) and (5) of the GARCH regression suffered from simultaneous equation bias because equation (6) was not part of the system. Separate estimations of the reaction function (6) routinely indicated that interventions were triggered by changes in returns, underlining the endogeneity problem in equation (4). The conditional volatility equation on the other hand seemed to be statistically fine since volatility (squared daily returns or fitted GARCH series) did not seem to influence interventions in the reaction function estimation. Therefore, the estimated coefficients of the mean equation of the GARCH model could not be interpreted.

Realized volatility allows us to treat $\sigma_{t}^{2}$ as an observed variable rather than as a latent variable and set up a system of equations. Multiple equation models have been employed before to analyze the effects of interventions on exchange rates (Kim 2003, Kearns and Rigobon 2005, Neely 2005). Our contribution to this literature is that we include volatility in the system and therefore disentangle the interplay of returns, volatility, and interventions. This resolves the endogeneity problem of the approach using GARCH and exogenous interventions.

${ }^{3}$ Note, however, that Japanese money market interest rates became almost zero in early 1999 and did not change substantially since then. 


\subsection{Identification}

Model (4) through (6) has 16 structural parameters to be estimated. To identify these structural parameters, we need 16 parameters in a reduced-form model

$$
y_{t}=\Phi x_{t}+\varepsilon_{t},
$$

where $y_{t}=\left(r_{t}, \log \sigma_{t}^{2}, I_{t}\right)$ is the vector of endogenous variables, $x_{t}$ is a vector of exogenous or pre-determined variables, and $\varepsilon_{t}$ is white noise. The exogenous variables in the system are the returns and squared returns of the Nikkei. The lags of realized volatility sampled at weekly and monthly frequency are predetermined. Given the three equations and four exogenous or pre-determined variables, the model has twelve reduced-form parameters. Therefore, for the system to be identified, we need to supply two instrumental variables, increasing the number of reduced-form model parameters to 18.

Using the third equation of the system as an example, a valid instrument is a variable $z_{t}$ that decomposes $w_{t}$ into

$$
w_{t}=\gamma_{6} z_{t}+w_{t}^{\prime}
$$

such that $\operatorname{cov}\left(z_{t}, w_{t}^{\prime}\right)=0$ by construction. Further, by assumption, $\operatorname{cov}\left(z_{t}, v_{t}\right)=$ 0 and $\operatorname{cov}\left(z_{t}, u_{t}\right)=0$ must hold. Then, the instrumental variable estimators of the parameters $\alpha_{1}$ and $\beta_{4}$ of main interest are given by

$$
\alpha_{1}=\frac{\operatorname{cov}\left(z_{t}, r_{t}\right)}{\operatorname{cov}\left(z_{t}, I_{t}\right)}, \quad \text { and } \quad \beta_{4}=\frac{\operatorname{cov}\left(z_{t}, \log \sigma_{t}^{2}\right)}{\operatorname{cov}\left(z_{t}, I_{t}\right)} .
$$

In order for the instrumental variable estimators to exist, the instrument $z_{t}$ must correlate with the intervention $I_{t}$. Only if the instrument $z_{t}$ also correlates with $r_{t}$ and $\log \sigma_{t}^{2}$, the estimators will not be zero. This correlation with $r_{t}$ and $\log \sigma_{t}^{2}$ must be through $I_{t}$ only, because the instrument $z_{t}$ must not correlate with any of the errors $u_{t}, v_{t}$ and $w_{t}^{\prime}$.

We propose lags of the intervention variable $z_{t}:=\left(I_{t-2}, I_{t-3}\right)$ as instruments. Many studies have shown that daily intervention data have significant low order autocorrelations and the first few lags are routinely included in the 
specification of reaction functions (e.g., Ito 2003, Dominguez 1998). Therefore, $\left(I_{t-2}, I_{t-3}\right)$ fulfill the condition $\operatorname{cov}\left(I_{t}, z_{t}\right) \neq 0$. By equations (4) and $(5), z_{t}$ will also correlate with $r_{t}$ and $\log \sigma_{t}^{2}$, such that the instrumental variable estimators will not be zero. The sample partial autocorrelation function for the Japanese intervention series drops off after the first two lags, so that $\operatorname{cov}\left(z_{t}, w_{t}^{\prime}\right)=0$ does not seem too much of a stretch. The zero correlation with the shocks $u_{t}$ and $v_{t}$ means that the interventions at lags 2 and 3 do not lead to shocks to exchange rate returns and volatility today. This seems reasonable if surprising interventions unfold their immediate effect on the day of the intervention and possibly one day later. Note that this assumption does not preclude systematic long term effects of interventions on the returns and volatility. These are still captured by the first lag of interventions in equation (6).

An alternative instrument that is discussed in the literature is announcements about major macroeconomic variables, in particular trade balances (Neely 2005). This variable correlates with the exchange rate $r_{t}$ and is used to instrumentalize equation (4). To be a valid instrument, it then must not correlate with the residual error in the mean equation $\left(\operatorname{cov}\left(z_{t}, u_{t}^{\prime}\right)=0\right)$, with shocks to interventions $\left(\operatorname{cov}\left(z_{t}, w_{t}\right)=0\right)$, and with shocks to volatility $\left(\operatorname{cov}\left(z_{t}, v_{t}\right)=0\right)$. In particular the latter requirement is unlikely to be fulfilled for this instrument. In Neely (2005) this does not pose a problem since that study does not consider volatility.

An entirely different approach to solve the identification problem is the twosegment threshold intervention model of Kearns and Rigobon (2005) that they estimate by simulated method of moments. Their setup also does not consider volatility. It allows for changes in the threshold intervention only, all other coefficients remain constant. Earlier studies have shown that both the reaction of the exchange rate returns to intervention (Ito 2003) and the reaction of volatility to intervention (Hillebrand and Schnabl 2006) varies with time, therefore Kearns' and Rigobon's approach is not appropriate for our problem. 


\subsection{Estimation}

The system (4) through (6) is estimated using the instruments $z_{t}=\left(I_{t-2}, I_{t-3}\right)$. Because of the unique structure of the intervention time series that has a substantial probability point mass at zero, we employ a GMM approach that does not require a specific distribution assumption for the error. We use a heteroskedasticity and autocorrelation consistent estimator with quadratic spectral kernel for the covariance matrix of the moment conditions and bandwidth selected according to Newey and West (1994). Tables 1 and 2 report the results for the sub-samples identified by the change-point detection in Section 4 .

Table 1: Estimation of Model (4) Through (6) For SAmple 2-Jan-1995 THROUGH 1-DEC-1999.

\begin{tabular}{cclcccc}
\hline \hline dep. var. & coeff. & indep. var. & estimate & std. err. & t-stat. & prob. \\
\hline$r_{t}$ & $\alpha_{0}$ & const & 0.0421 & 0.0203 & 2.0771 & 0.0379 \\
& $\alpha_{1}$ & $I_{t}$ & -0.3218 & 0.1078 & -2.9863 & 0.0028 \\
& $\alpha_{2}$ & $r_{t, \text { Nikkei }}$ & -0.0262 & 0.0171 & -1.5335 & 0.1252 \\
$\log \sigma_{t}^{2}$ & $\beta_{0}$ & const & -0.8706 & 0.0815 & -10.6825 & 0.0000 \\
& $\beta_{1}$ & $\log \sigma_{t-1}^{2}$ & 0.3986 & 0.0317 & 12.5770 & 0.0000 \\
& $\beta_{2}$ & $\log \sigma_{t-1, w}^{2}$ & 0.2556 & 0.0423 & 6.0475 & 0.0000 \\
& $\beta_{3}$ & $\log \sigma_{t-1, m}^{2}$ & 0.1489 & 0.0350 & 4.2593 & 0.0000 \\
& $\beta_{4}$ & $I_{t}$ & 0.3950 & 0.1053 & 3.7517 & 0.0002 \\
& $\beta_{5}$ & $r_{t, \text { Nikkei }}^{2}$ & 0.7708 & 0.1341 & 5.7478 & 0.0000 \\
& $\gamma_{1}$ & $I_{t-1}$ & 0.2226 & 0.0713 & 3.1204 & 0.0018 \\
& $\gamma_{2}$ & $r_{t}$ & 1.7675 & 0.8200 & 2.1554 & 0.0312 \\
& $\gamma_{3}$ & $r_{t-1}$ & -0.1167 & 0.0665 & -1.7533 & 0.0796 \\
& $\gamma_{4}$ & $\sigma_{t}^{2}$ & 0.0439 & 0.1993 & 0.2200 & 0.8259 \\
& $\gamma_{5}$ & $\sigma_{t-1}^{2}$ & -0.0246 & 0.1967 & -0.1248 & 0.9007 \\
& $\gamma_{6}$ & $r_{t, \text { Nikkei }}$ & 0.0535 & 0.0440 & 1.2164 & 0.2239 \\
& $\gamma_{7}$ & $r_{t, \text { Nikkei }}^{2}$ & 0.3501 & 0.5551 & 0.6307 & 0.5283 \\
\hline
\end{tabular}


There are two concepts of "success" of interventions discussed in the literature: Either (1) interventions push the exchange rate in the desired direction or (2) interventions reduce volatility. The desired direction in the case of Japan is a depreciation of the yen most of the time. ${ }^{4}$ For the case (1) of returns on the yen/dollar rate, this means that interventions should have a significantly positively estimated coefficient.

Judging by these standards, interventions have not done well on the first segment between 1995 and 1999: The coefficient $\alpha_{1}$ of interventions in the returns equation (4) is significantly negative; it has the wrong sign. The coefficient $\beta_{4}$ of interventions in the log realized volatility equation (5) is significantly positive. We cannot conclude that interventions caused an appreciation of the yen and an increase in volatility: The statistical method can still only capture correlations. The simultaneity of the system estimation, however, ensures that the estimates do not suffer from endogeneity bias. The interventions clearly did not prevent movements in the direction opposite to the desired one. The reaction function (6) displays significant coefficients for the returns and insignificant coefficients for volatility, confirming the results commonly found in the literature.

On the second segment from 2-Dec-1999 to 30-Dec-2004, interventions have a marginally significant positive coefficient $\alpha_{1}$ in the return equation (4) and a highly significant negative coefficient $\beta_{4}$ in the volatility equation (5). These are the expected signs for a successful intervention that depreciates the yen and reduces volatility. The reduction in volatility is more convincing than the influence on the returns, however, if judged by the significance of the estimated coefficients.

Estimated on the entire sample 2-Jan-1995 through 30-Dec-2004, the coefficient $\alpha_{1}$ of interventions in the return equation (4) is insignificant. The estimated coefficient $\beta_{4}$ in the volatility equation (5) is highly significantly negative.

\footnotetext{
${ }^{4}$ On 10-Apr-1998, the Japanese monetary authorities sold $\$ 20.4 \mathrm{bn}$. This is the only instance in our sample where an intervention to appreciate the yen against the dollar was undertaken. Deleting this "outlier" does not substantially change the results.
} 
Table 2: Estimation of Model (4) Through (6) For SAmple 2-DeC-1999 THROUGH 30-DEC-2004.

\begin{tabular}{cclcccc}
\hline \hline dep. var. & coeff. & indep. var. & estimate & std. err. & t-stat. & prob. \\
\hline$r_{t}$ & $\alpha_{0}$ & const & 0.0029 & 0.0166 & 0.1776 & 0.8590 \\
& $\alpha_{1}$ & $I_{t}$ & 0.0302 & 0.0158 & 1.9132 & 0.0558 \\
& $\alpha_{2}$ & $r_{t, \text { Nikkei }}$ & -0.0374 & 0.0147 & -2.5491 & 0.0108 \\
$\log \sigma_{t}^{2}$ & $\beta_{0}$ & const & -1.0477 & 0.1868 & -5.6082 & 0.0000 \\
& $\beta_{1}$ & $\log \sigma_{t-1}^{2}$ & 0.2560 & 0.0401 & 6.3889 & 0.0000 \\
& $\beta_{2}$ & $\log \sigma_{t-1, w}^{2}$ & 0.3039 & 0.0754 & 4.0331 & 0.0001 \\
& $\beta_{3}$ & $\log \sigma_{t-1, m}^{2}$ & 0.2252 & 0.0573 & 3.9316 & 0.0001 \\
& $\beta_{4}$ & $I_{t}$ & -0.1198 & 0.0246 & -4.8777 & 0.0000 \\
& $\beta_{5}$ & $r_{t, \text { Nikkei }}^{2}$ & 0.5346 & 0.1411 & 3.7884 & 0.0002 \\
& $\gamma_{1}$ & $I_{t-1}$ & 0.3470 & 0.0526 & 6.5987 & 0.0000 \\
& $\gamma_{2}$ & $r_{t}$ & 0.1526 & 1.7858 & 0.0854 & 0.9319 \\
& $\gamma_{3}$ & $r_{t-1}$ & -0.1170 & 0.1295 & -0.9035 & 0.3663 \\
& $\gamma_{4}$ & $\sigma_{t}^{2}$ & 0.1224 & 0.1713 & 0.7141 & 0.4752 \\
& $\gamma_{5}$ & $\sigma_{t-1}^{2}$ & -0.1427 & 0.1721 & -0.8293 & 0.4070 \\
& $\gamma_{6}$ & $r_{t, \text { Nikkei }}$ & 0.0094 & 0.0516 & 0.1818 & 0.8557 \\
& $\gamma_{7}$ & $r_{t, \text { Nikkei }}^{2}$ & -0.0238 & 0.4762 & -0.0501 & 0.9601 \\
\hline
\end{tabular}


These estimates are not reported for brevity.

The extant literature discusses several possible causes for a change in the effects of interventions. Among these are, to name a few, a change in the intervention policy from frequent small to infrequent large interventions (Ito 2003), the deregulation of the Japanese foreign exchange market (Ito and Melvin 1999), and a switch from sterilized interventions to factually unsterilized interventions in the liquidity trap (Hillebrand and Schnabl 2006). The timing of these events differs widely, though, and does not coincide conclusively with the change-point found in 1999 in Section 4. We do not intend to be authoritative about any of these possible causes, the contribution of this study is methodological.

Another potentially important channel for interventions of the Japanese monetary authorities in the yen/dollar market is the interest rate. Tables 3 and 4 report estimations of the system (4) through (6) including concurrent and lagged values of the Japanese uncollateralized overnight interbank rate $i_{t, j a p}$ as

well as the interest rate differential with the US Federal Funds Rate $i_{t, \mathrm{US}}-i_{t, \mathrm{jap}}$. The estimated coefficients are insignificant throughout in the first sub-sample. In the second sub-sample, the interest rate differential is marginally significant in equations (4) and (6), but the signs are inconclusive. On the total sample (not reported) all coefficients of the interest rate variables are insignificant. The interest rate does not seem to be a direct channel of intervention policy in the yen/dollar market.

\section{Conclusion}

We examine the interplay of returns and realized volatility of the yen/dollar exchange rate with interventions of the Japanese monetary authorities in the yen/dollar market. The concept of realized volatility allows us to treat volatility as an observed variable and enables us to employ a simultaneous equations model for returns, realized volatility, and interventions. This resolves the endogeneity 
Table 3: Estimation of model (4) Through (6) For Sample 4-Nov-1996 THROUGH 1-DEC-1999.

\begin{tabular}{|c|c|c|c|c|c|c|}
\hline dep. var. & coeff. & indep. var. & estimate & std. err. & t-stat. & prob. \\
\hline \multirow[t]{7}{*}{$r_{t}$} & $\alpha_{0}$ & const & 0.1638 & 0.3220 & 0.5086 & 0.6111 \\
\hline & $\alpha_{1}$ & $I_{t}$ & -0.1823 & 0.0870 & -2.0962 & 0.0362 \\
\hline & $\alpha_{2}$ & $r_{t, \text { Nikkei }}$ & -0.0600 & 0.0180 & -3.3365 & 0.0009 \\
\hline & $\alpha_{3}$ & $i_{t, \text { jap }}$ & -0.5365 & 0.9948 & -0.5393 & 0.5897 \\
\hline & $\alpha_{4}$ & $i_{t, \mathrm{US}}-i_{t, \mathrm{jap}}$ & -0.1016 & 0.0933 & -1.0900 & 0.2758 \\
\hline & $\alpha_{5}$ & $i_{t-1, \mathrm{jap}}$ & -1.2157 & 0.9487 & -1.2814 & 0.2002 \\
\hline & $\alpha_{6}$ & $i_{t-1, \mathrm{US}}-i_{t-1, \mathrm{jap}}$ & 0.0766 & 0.0904 & 0.8475 & 0.3968 \\
\hline \multirow[t]{10}{*}{$\log \sigma_{t}^{2}$} & $\beta_{0}$ & const & -0.7857 & 0.2425 & -3.2395 & 0.0012 \\
\hline & $\beta_{1}$ & $\log \sigma_{t-1}^{2}$ & 0.3783 & 0.0323 & 11.700 & 0.0000 \\
\hline & $\beta_{2}$ & $\log \sigma_{t-1, w}^{2}$ & 0.2467 & 0.0484 & 5.0926 & 0.0000 \\
\hline & $\beta_{3}$ & $\log \sigma_{t-1, m}^{2}$ & 0.1822 & 0.0417 & 4.3644 & 0.0000 \\
\hline & $\beta_{4}$ & $I_{t}$ & 0.5863 & 0.1264 & 4.6373 & 0.0000 \\
\hline & $\beta_{5}$ & $r_{t, \text { Nikkei }}^{2}$ & 0.8679 & 0.1538 & 5.6444 & 0.0000 \\
\hline & $\beta_{6}$ & $i_{t, \text { jap }}$ & -0.3854 & 0.5212 & -0.7394 & 0.4597 \\
\hline & $\beta_{7}$ & $i_{t, \mathrm{US}}-i_{t, \mathrm{jap}}$ & -0.0581 & 0.0516 & -1.1257 & 0.2604 \\
\hline & $\beta_{8}$ & $i_{t-1, \mathrm{jap}}$ & 0.1699 & 0.4372 & 0.3887 & 0.6976 \\
\hline & $\beta_{9}$ & $i_{t-1, \mathrm{US}}-i_{t-1, \mathrm{jap}}$ & 0.0459 & 0.0587 & 0.7824 & 0.4340 \\
\hline \multirow[t]{11}{*}{$I_{t}$} & $\gamma_{1}$ & $I_{t-1}$ & 0.1299 & 0.0197 & 6.5807 & 0.0000 \\
\hline & $\gamma_{2}$ & $r_{t}$ & 0.5537 & 0.1268 & 4.3667 & 0.0000 \\
\hline & $\gamma_{3}$ & $r_{t-1}$ & -0.0544 & 0.0340 & -1.6000 & 0.1097 \\
\hline & $\gamma_{4}$ & $\sigma_{t}^{2}$ & 0.0852 & 0.0898 & 0.9484 & 0.3430 \\
\hline & $\gamma_{5}$ & $\sigma_{t-1}^{2}$ & -0.0447 & 0.0884 & -0.5059 & 0.6130 \\
\hline & $\gamma_{6}$ & $r_{t, \text { Nikkei }}$ & 0.0316 & 0.0197 & 1.6087 & 0.1078 \\
\hline & $\gamma_{7}$ & $r_{t, \text { Nikkei }}^{2}$ & -0.2320 & 0.2677 & -0.8665 & 0.3863 \\
\hline & $\gamma_{8}$ & $i_{t, \text { jap }}$ & 0.6111 & 0.8474 & 0.7212 & 0.4709 \\
\hline & $\gamma_{9}$ & $i_{t, \mathrm{US}}-i_{t, \mathrm{jap}}$ & -0.0070 & 0.0654 & -0.1072 & 0.9146 \\
\hline & $\gamma_{10}$ & $i_{t-1, \text { jap }}$ & 0.9338 & 0.7898 & 1.1824 & 0.2372 \\
\hline & $\gamma_{11}$ & $i_{t-1, \mathrm{US}}-i_{t-1, \mathrm{jap}}$ & 0.0349 & 0.0701 & 0.4975 & 0.6189 \\
\hline
\end{tabular}


Table 4: Estimation of model (4) through (6) For sample 2-Dec-1999 THROUGH 30-DeC-2004.

\begin{tabular}{|c|c|c|c|c|c|c|}
\hline dep. var. & coeff. & indep. var. & estimate & std. err. & t-stat. & prob. \\
\hline \multirow[t]{7}{*}{$r_{t}$} & $\alpha_{0}$ & const & -0.0570 & 0.0284 & -2.0079 & 0.0447 \\
\hline & $\alpha_{1}$ & $I_{t}$ & 0.0498 & 0.0124 & 4.0118 & 0.0001 \\
\hline & $\alpha_{2}$ & $r_{t, \text { Nikkei }}$ & -0.0398 & 0.0146 & -2.7258 & 0.0064 \\
\hline & $\alpha_{3}$ & $i_{t, \mathrm{jap}}$ & 1.6074 & 1.3247 & 1.2134 & 0.2250 \\
\hline & $\alpha_{4}$ & $i_{t, \mathrm{US}}-i_{t, \mathrm{jap}}$ & -0.1470 & 0.0854 & -1.7198 & 0.0855 \\
\hline & $\alpha_{5}$ & $i_{t-1, \mathrm{jap}}$ & 0.4010 & 1.2329 & 0.3252 & 0.7450 \\
\hline & $\alpha_{6}$ & $i_{t-1, \mathrm{US}}-i_{t-1, \mathrm{jap}}$ & 0.1647 & 0.0859 & 1.9168 & 0.0553 \\
\hline \multirow[t]{10}{*}{$\log \sigma_{t}^{2}$} & $\beta_{0}$ & const & -1.1814 & 0.2044 & -5.7785 & 0.0000 \\
\hline & $\beta_{1}$ & $\log \sigma_{t-1}^{2}$ & 0.2534 & 0.0392 & 6.4685 & 0.0000 \\
\hline & $\beta_{2}$ & $\log \sigma_{t-1, w}^{2}$ & 0.3098 & 0.0715 & 4.3304 & 0.0000 \\
\hline & $\beta_{3}$ & $\log \sigma_{t-1, m}^{2}$ & 0.1951 & 0.0580 & 3.3630 & 0.0008 \\
\hline & $\beta_{4}$ & $I_{t}$ & -0.1215 & 0.0227 & -5.3589 & 0.0000 \\
\hline & $\beta_{5}$ & $r_{t, \text { Nikkei }}^{2}$ & 0.6157 & 0.1458 & 4.2240 & 0.0000 \\
\hline & $\beta_{6}$ & $i_{t, \mathrm{jap}}$ & 0.5751 & 0.7310 & 0.7868 & 0.4314 \\
\hline & $\beta_{7}$ & $i_{t, \mathrm{US}}-i_{t, \mathrm{jap}}$ & 0.1286 & 0.0868 & 1.4815 & 0.1385 \\
\hline & $\beta_{8}$ & $i_{t-1, \mathrm{jap}}$ & -0.8153 & 0.4469 & -1.8244 & 0.0682 \\
\hline & $\beta_{9}$ & $i_{t-1, \mathrm{US}}-i_{t-1, \mathrm{jap}}$ & -0.1245 & 0.0869 & -1.4334 & 0.1518 \\
\hline \multirow[t]{11}{*}{$I_{t}$} & $\gamma_{1}$ & $I_{t-1}$ & 0.2474 & 0.0563 & 4.3967 & 0.0000 \\
\hline & $\gamma_{2}$ & $r_{t}$ & 8.2418 & 2.2070 & 3.7344 & 0.0002 \\
\hline & $\gamma_{3}$ & $r_{t-1}$ & 0.0931 & 0.1526 & 0.6098 & 0.5420 \\
\hline & $\gamma_{4}$ & $\sigma_{t}^{2}$ & -0.1474 & 0.2133 & -0.6909 & 0.4897 \\
\hline & $\gamma_{5}$ & $\sigma_{t-1}^{2}$ & 0.0258 & 0.1840 & 0.1402 & 0.8885 \\
\hline & $\gamma_{6}$ & $r_{t, \text { Nikkei }}$ & 0.3032 & 0.1132 & 2.6779 & 0.0074 \\
\hline & $\gamma_{7}$ & $r_{t, \text { Nikkei }}^{2}$ & 0.2476 & 0.5113 & 0.4844 & 0.6281 \\
\hline & $\gamma_{8}$ & $i_{t, \mathrm{jap}}$ & -12.747 & 9.3519 & -1.3631 & 0.1729 \\
\hline & $\gamma_{9}$ & $i_{t, \mathrm{US}}-i_{t, \mathrm{jap}}$ & 1.1856 & 0.6603 & 1.7957 & 0.0726 \\
\hline & $\gamma_{10}$ & $i_{t-1, \mathrm{jap}}$ & -2.4283 & 8.0821 & -0.3005 & 0.7638 \\
\hline & $\gamma_{11}$ & $i_{t-1, \mathrm{US}}-i_{t-1, \mathrm{jap}}$ & -1.3484 & 0.6820 & -1.9771 & 0.0481 \\
\hline
\end{tabular}


problem that plagued earlier approaches to measure the success of interventions.

We find a change-point in the time series of realized volatility of the yen/dollar exchange rate in Dec 1999. We estimate the system of equations on the resulting sub-periods using GMM. The results show that during the first subperiod from 1995 through 1999, interventions were unsuccessful in devaluating the yen against the dollar and reducing volatility. On the second sub-period 1999 through 2004, the estimated coefficients are consistent with interventions that depreciate the yen and reduce exchange rate volatility.

\section{Acknowledgments}

The idea for this paper was the result of a conversation with Marcelo Medeiros. We gratefully acknowledge the comments from participants of the CIREQ Conference on Realized Volatility in Montreal 2006, in particular Greg Bauer, Tim Bollerslev, and Peter Reinhard Hansen, as well as from the participants of the Realized Volatility Conference in Konstanz in 2006, in particular Eric Renault. These comments have substantially improved the paper. All remaining errors are ours. 


\section{References}

Andersen, T. G. and T. Bollerslev (1998) "Answering the Skeptics: Yes, Standard Volatility Models Do Provide Accurate Forecasts," International Economic Review 39(4), 885-905.

Andersen, T. G., Bollerslev, T., Diebold, F. X., and P. Labys (2001) "The Distribution of Realized Exchange Rate Volatility," Journal of the American Statistical Association 96(453), 42-55.

Andersen, T. G., Bollerslev, T., Diebold, F. X., and H. Ebens (2001) "The Distribution of Realized Stock Return Volatility," Journal of Financial Economics 61, 43-76.

Andreou, E. and E. Ghysels (2002) "Detecting multiple breaks in financial market volatility dynamics," Journal of Applied Econometrics 17, 579600 .

Bai, J. (1994) "Least Squares Estimation of a Shift in Linear Processes," Journal of Time Series Analysis 15(5), 453-472.

Bai, J. (1997) "Estimating Multiple Breaks One at a Time," Econometric Theory $13,315-352$.

Barndorff-Nielsen, O. E. and N. Shephard (2002) "Econometric analysis of realized volatility and its use in estimating stochastic volatility models," Journal of the Royal Statistical Society B, 64(2), 253-280.

Bonser-Neal, C. and G. Tanner (1996) "Central Bank Intervention and the Volatility of Foreign Exchange Rates: Evidence from the Options Market," Journal of International Money and Finance 15, 853-878.

Bos, C. S., Franses, P. H. and M. Ooms (1999) "Long memory and level shifts: Re-analyzing inflation rates," Empirical Economics 24, 427-449.

Corsi, F. (2004) "A Simple Long Memory Model of Realized Volatility," manuscript, University of Lugano. 
Den Haan, W. and A. Levin. (1997) "A Practitioner's Guide to Robust Covariance Matrix Estimation," in G. Maddala and C. Rao (eds.), Handbook of Statistics Vol. 15: Robust Inference, Amsterdam: North-Holland.

Diebold, F. X. and A. Inoue (2001) "Long memory and regime switching," Journal of Econometrics 105, 131-159.

Dominguez, K. (1998) "Central Bank Intervention and Exchange Rate Volatility," Journal of International Money and Finance 17, 161-190.

Fatum, R. and M. Hutchison (2003) "Is Sterilized Foreign Exchange Intervention Successful after All? An Event Study Approach." Economic Journal $113,390-411$.

Frenkel, M., Pierdzioch, C., and G. Stadtmann (2005) "The Effects of Japanese Foreign Exchange Market Interventions on the Yen/U.S. Dollar Exchange Rate Volatility," International Review of Economics and Finance 14, 2739.

Granger, C. W. J. and N. Hyung (1999) "Occasional structural breaks and long memory," UC San Diego Discussion Paper 99-14.

Hillebrand, E. (2005) "Neglecting Parameter Changes in GARCH Models," Journal of Econometrics 129, 121-138.

Hillebrand, E. and G. Schnabl (2006) "A Structural Break in the Effects of Japanese Foreign Exchange Intervention on Yen/Dollar Exchange Rate Volatility," European Central Bank Working Paper 650.

Ito, T. (2003) "Is Foreign Exchange Intervention Effective? The Japanese Experience in the 1990s." In Paul Mizen (ed.) Monetary History, Exchange Rates and Financial Markets. Essays in Honour of Charles Goodhart, Vol. 2, pp. 126-153.

Ito, T. and M. Melvin (1999) "Japan's Big Bang and the Transformation of Fi-nancial Markets," NBER Working Paper 7247. 
Kearns, J. and R. Rigobon (2005) "Identifying the Efficacy of Central Bank Interventions: Evidence from Australia and Japan," Journal of International Economics 66(1), 31-48.

Kim, S. (2003) "Monetary Policy, Foreign Exchange Intervention, and the Exchange Rate in a Unifying Framework," Journal of International Economics $60,355-386$.

Lamoureux, C. G. and W. D. Lastrapes (1990) "Persistence in variance, structural change, and the GARCH model," Journal of Business and Economic Statistics 8, 225-234.

LeBaron, B. (2001) "Stochastic volatility as a simple generator of apparent financial power laws and long memory," Quantitative Finance 1, 621-631.

Mikosch, T. and C. Starica (2004) "Nonstationarities in Financial Time Series, the Long-Range Dependence, and the IGARCH Effects," Review of Economics and Statistics 86(1), 378-390.

Neely, C. J. (2005) "Identifying the Effects of U.S. Intervention on the Levels of Exchange Rates," Federal Reserve Bank of St. Louis Working Paper 2005-031B.

Newey, W. and K. West (1994) "Automatic Lag Selection in Covariance Matrix Estimation," Review of Economic Studies 61, 631-653.

Watanabe, T. and K. Harada (2006) "Effects of the Bank of Japan's Intervention on Yen/Dollar Exchange Rate Volatility," Journal of Japanese and International Economies 20, 99-111. 


\title{
CESifo Working Paper Series
}

\author{
(for full list see www.cesifo-group.de)
}

1705 Piero Gottardi and Felix Kubler, Social Security and Risk Sharing, April 2006

1706 Giacomo Corneo and Christina M. Fong, What's the Monetary Value of Distributive Justice?, April 2006

1707 Andreas Knabe, Ronnie Schoeb and Joachim Weimann, Marginal Employment Subsidization: A New Concept and a Reappraisal, April 2006

1708 Hans-Werner Sinn, The Pathological Export Boom and the Bazaar Effect - How to Solve the German Puzzle, April 2006

1709 Helge Berger and Stephan Danninger, The Employment Effects of Labor and Product Markets Deregulation and their Implications for Structural Reform, May 2006

1710 Michael Ehrmann and Marcel Fratzscher, Global Financial Transmission of Monetary Policy Shocks, May 2006

1711 Carsten Eckel and Hartmut Egger, Wage Bargaining and Multinational Firms in General Equilibrium, May 2006

1712 Mathias Hoffmann, Proprietary Income, Entrepreneurial Risk, and the Predictability of U.S. Stock Returns, May 2006

1713 Marc-Andreas Muendler and Sascha O. Becker, Margins of Multinational Labor Substitution, May 2006

1714 Surajeet Chakravarty and W. Bentley MacLeod, Construction Contracts (or "How to Get the Right Building at the Right Price?”), May 2006

1715 David Encaoua and Yassine Lefouili, Choosing Intellectual Protection: Imitation, Patent Strength and Licensing, May 2006

1716 Chris van Klaveren, Bernard van Praag and Henriette Maassen van den Brink, Empirical Estimation Results of a Collective Household Time Allocation Model, May 2006

1717 Paul De Grauwe and Agnieszka Markiewicz, Learning to Forecast the Exchange Rate: Two Competing Approaches, May 2006

1718 Sijbren Cnossen, Tobacco Taxation in the European Union, May 2006

1719 Marcel Gérard and Fernando Ruiz, Interjurisdictional Competition for Higher Education and Firms, May 2006 
1720 Ronald McKinnon and Gunther Schnabl, China's Exchange Rate and International Adjustment in Wages, Prices, and Interest Rates: Japan Déjà Vu?, May 2006

1721 Paolo M. Panteghini, The Capital Structure of Multinational Companies under Tax Competition, May 2006

1722 Johannes Becker, Clemens Fuest and Thomas Hemmelgarn, Corporate Tax Reform and Foreign Direct Investment in Germany - Evidence from Firm-Level Data, May 2006

1723 Christian Kleiber, Martin Sexauer and Klaus Waelde, Bequests, Taxation and the Distribution of Wealth in a General Equilibrium Model, May 2006

1724 Axel Dreher and Jan-Egbert Sturm, Do IMF and World Bank Influence Voting in the UN General Assembly?, May 2006

1725 Swapan K. Bhattacharya and Biswa N. Bhattacharyay, Prospects of Regional Cooperation in Trade, Investment and Finance in Asia: An Empirical Analysis on BIMSTEC Countries and Japan, May 2006

1726 Philippe Choné and Laurent Linnemer, Assessing Horizontal Mergers under Uncertain Efficiency Gains, May 2006

1727 Daniel Houser and Thomas Stratmann, Selling Favors in the Lab: Experiments on Campaign Finance Reform, May 2006

1728 E. Maarten Bosker, Steven Brakman, Harry Garretsen and Marc Schramm, A Century of Shocks: The Evolution of the German City Size Distribution 1925 - 1999, May 2006

1729 Clive Bell and Hans Gersbach, Growth and Enduring Epidemic Diseases, May 2006

1730 W. Bentley MacLeod, Reputations, Relationships and the Enforcement of Incomplete Contracts, May 2006

1731 Jan K. Brueckner and Ricardo Flores-Fillol, Airline Schedule Competition: ProductQuality Choice in a Duopoly Model, May 2006

1732 Kerstin Bernoth and Guntram B. Wolff, Fool the Markets? Creative Accounting, Fiscal Transparency and Sovereign Risk Premia, May 2006

1733 Emmanuelle Auriol and Pierre M. Picard, Government Outsourcing: Public Contracting with Private Monopoly, May 2006

1734 Guglielmo Maria Caporale and Luis A. Gil-Alana, Modelling Structural Breaks in the US, UK and Japanese Unemployment Rates, May 2006

1735 Emily J. Blanchard, Reevaluating the Role of Trade Agreements: Does Investment Globalization Make the WTO Obsolete?, May 2006

1736 Per Engström and Bertil Holmlund, Tax Evasion and Self-Employment in a High-Tax Country: Evidence from Sweden, May 2006 
1737 Erkki Koskela and Mikko Puhakka, Cycles and Indeterminacy in Overlapping Generations Economies with Stone-Geary Preferences, May 2006

1738 Saku Aura and Thomas Davidoff, Supply Constraints and Housing Prices, May 2006

1739 Balázs Égert and Ronald MacDonald, Monetary Transmission Mechanism in Transition Economies: Surveying the Surveyable, June 2006

1740 Ben J. Heijdra and Ward E. Romp, Ageing and Growth in the Small Open Economy, June 2006

1741 Robert Fenge and Volker Meier, Subsidies for Wages and Infrastructure: How to Restrain Undesired Immigration, June 2006

1742 Robert S. Chirinko and Debdulal Mallick, The Elasticity of Derived Demand, Factor Substitution and Product Demand: Corrections to Hicks' Formula and Marshall's Four Rules, June 2006

1743 Harry P. Bowen, Haris Munandar and Jean-Marie Viaene, Evidence and Implications of Zipf's Law for Integrated Economies, June 2006

1744 Markku Lanne and Helmut Luetkepohl, Identifying Monetary Policy Shocks via Changes in Volatility, June 2006

1745 Timo Trimborn, Karl-Josef Koch and Thomas M. Steger, Multi-Dimensional Transitional Dynamics: A Simple Numberical Procedure, June 2006

1746 Vivek H. Dehejia and Yiagadeesen Samy, Labor Standards and Economic Integration in the European Union: An Empirical Analysis, June 2006

1747 Carlo Altavilla and Paul De Grauwe, Forecasting and Combining Competing Models of Exchange Rate Determination, June 2006

1748 Olaf Posch and Klaus Waelde, Natural Volatility, Welfare and Taxation, June 2006

1749 Christian Holzner, Volker Meier and Martin Werding, Workfare, Monitoring, and Efficiency Wages, June 2006

1750 Steven Brakman, Harry Garretsen and Charles van Marrewijk, Agglomeration and Aid, June 2006

1751 Robert Fenge and Jakob von Weizsäcker, Mixing Bismarck and Child Pension Systems: An Optimum Taxation Approach, June 2006

1752 Helge Berger and Michael Neugart, Labor Courts, Nomination Bias, and Unemployment in Germany, June 2006

1753 Chris van Klaveren, Bernard van Praag and Henriette Maassen van den Brink, A Collective Household Model of Time Allocation - a Comparison of Native Dutch and Immigrant Households in the Netherlands, June 2006 
1754 Marko Koethenbuerger, Ex-Post Redistribution in a Federation: Implications for Corrective Policy, July 2006

1755 Axel Dreher, Jan-Egbert Sturm and Heinrich Ursprung, The Impact of Globalization on the Composition of Government Expenditures: Evidence from Panel Data, July 2006

1756 Richard Schmidtke, Private Provision of a Complementary Public Good, July 2006

1757 J. Atsu Amegashie, Intentions and Social Interactions, July 2006

1758 Alessandro Balestrino, Tax Avoidance, Endogenous Social Norms, and the Comparison Income Effect, July 2006

1759 Øystein Thøgersen, Intergenerational Risk Sharing by Means of Pay-as-you-go Programs - an Investigation of Alternative Mechanisms, July 2006

1760 Pascalis Raimondos-Møller and Alan D. Woodland, Steepest Ascent Tariff Reforms, July 2006

1761 Ronald MacDonald and Cezary Wojcik, Catching-up, Inflation Differentials and Credit Booms in a Heterogeneous Monetary Union: Some Implications for EMU and new EU Member States, July 2006

1762 Robert Dur, Status-Seeking in Criminal Subcultures and the Double Dividend of ZeroTolerance, July 2006

1763 Christa Hainz, Business Groups in Emerging Markets - Financial Control and Sequential Investment, July 2006

1764 Didier Laussel and Raymond Riezman, Fixed Transport Costs and International Trade, July 2006

1765 Rafael Lalive, How do Extended Benefits Affect Unemployment Duration? A Regression Discontinuity Approach, July 2006

1766 Eric Hillebrand, Gunther Schnabl and Yasemin Ulu, Japanese Foreign Exchange Intervention and the Yen/Dollar Exchange Rate: A Simultaneous Equations Approach Using Realized Volatility, July 2006 